\title{
BMJ Open Association between dementia and depression: a retrospective study using the Korean National Health Insurance Service-National Sample Cohort database
}

\author{
Ok-Cheol Yu, ${ }^{1}$ Boyoung Jung (DD , ${ }^{2}$ Hoyeon Go, ${ }^{3,4}$ Minjung Park, ${ }^{5}$ In-Hyuk Ha (D) ${ }^{6}$
}

To cite: Yu 0-C, Jung B, $\mathrm{Go} \mathrm{H}$, et al. Association between dementia and depression: a retrospective study using the Korean National Health Insurance Service-National Sample Cohort database. BMJ Open 2020;10:e034924. doi:10.1136/ bmjopen-2019-034924

- Prepublication history for this paper is available online To view these files, please visit the journal online (http://dx.doi org/10.1136/bmjopen-2019034924).

Received 11 October 2019 Revised 27 July 2020

Accepted 07 August 2020
Check for updates

(C) Author(s) (or their employer(s)) 2020. Re-use permitted under CC BY-NC. No commercial re-use. See rights and permissions. Published by BMJ.

For numbered affiliations see end of article.

Correspondence to

Dr In-Hyuk Ha;

hanihata@gmail.com

\section{ABSTRACT}

Objectives Dementia is common in people over the age of 65 years, with $80 \%$ of people with dementia older than 75 years. Previous studies have linked dementia to latelife depression, but the association between dementia and mid-life depression is poorly understood. Depression is a preventable and treatable medical condition, which means it is a modifiable factor that can potentially prevent or delay dementia. This study aimed to identify the association between dementia and depression within the life course.

Design A nationwide, retrospective propensity score matched cohort study associating dementia with depression. Depression diagnosed between the ages of 45 and 64 years was classified as 'mid-life' and 'late-life' if diagnosed at 65 years or older. Patients were considered to have depression when one or more International Statistical Classification of Diseases and Related Health Problems, 10th revision codes for depression were recorded as primary or secondary diagnosis.

Setting National Health Insurance Service-National Sample Cohort database of the National Health Insurance Service in South Korea, containing patient data from 2002 to 2013.

Participants The study included 1824 and 374852 patients in the case and control groups, respectively. A logistic regression analysis with complex sampling design was performed after adjusting for covariates, using the propensity score matching method without callipers, with a 1:1 nearest neighbour matching algorithm.

Primary and secondary outcome measures The association of mid-onset and late-onset depression with dementia in terms of sociodemographic characteristics, such as sex and age, within the Korean population.

Results Dementia was significantly associated with the presence of depression ( $\mathrm{OR}=2.20,95 \% \mathrm{Cl}=1.53-3.14)$; in particular, female patients with depression and patients aged 45-64 years with depression had increased odds of dementia $(\mathrm{OR}=2.65,95 \% \mathrm{Cl}=1.78-3.93$ and $\mathrm{OR}=2.72$, $95 \% \mathrm{Cl}=1.41-5.24$, respectively)

Conclusion Depression is an associated factor for dementia, especially among people aged 45-64 years (mid-life).
Strengths and limitations of this study

- Data were obtained from the National Health Insurance Service-National Sample Cohort (NHISNSC), a representative sample of Korea, and our findings on the relationship between dementia and depression is therefore reliable.

- Patients were included in the case group based on usage of International Statistical Classification of Diseases and Related Health Problems, 10th revision diagnostic codes, resulting in accurate results that reflect the actual medical environment.

- By analysing the 10-year follow-up data of patients diagnosed with depression through propensity scores, we ensured adequate statistical explanation.

- Our use of NHIS-NSC data rather than medical records, enabled us to control the association of various covariates with dementia, although diagnostic accuracy may be limited.

- It was not possible to confirm if the clinical intervention for depression was protective against the development of dementia.

\section{INTRODUCTION}

Dementia is a common condition affecting older adults, with $80 \%$ of those affected by dementia aged 75 years or older. ${ }^{1}$ Dementia causes a significant strain on national budgets; the worldwide economic burden of dementia was roughly US $\$ 818$ billion in 2015 and was estimated to increase to more than US $\$ 1$ trillion in $2018 .^{2}$ In the US alone, dementia was responsible for a total expense of US $\$ 277$ billion in 2018, and is expected to reach approximately US $\$ 1.1$ trillion in $2050 .{ }^{3}$ In Korea, about 15.2 trillion won (about 1\% of the gross domestic product (GDP)) were spent on dementia in 2020; this amount is predicted to reach 43.2 trillion won in 2050 (about $1.5 \%$ of the GDP). ${ }^{4}$

As the average life expectancy rises, the population ages and the economic burden 
of the dementia increases. ${ }^{5}$ In 2019, the number of people suffering from dementia worldwide was about 50 million; this number is estimated to reach 152 million in 2050. ${ }^{6}$ The prevalence of dementia among the elderly population (aged 65 years or older) in South Korea (referred to as Korea henceforth) is expected to increase from $10.28 \%$ in 2019 to $16.09 \%$ in 2050 , and the number of patients with dementia will be approximately 3 million in 2050 (15\% of the total elderly population). ${ }^{7}$

Depression is a common comorbid disorder in adults with dementia; in fact, $30 \%-50 \%$ of dementia cases are accompanied by depression. ${ }^{8}$ Clinically, depression and dementia are distinct but share some of the symptoms, such as decreased social and occupational functioning, attention deficit and impaired working memory. ${ }^{9}$ Due to these intrinsic similarities, it can be difficult to distinguish depression from dementia. Previous studies have reported that depression accelerates cognitive decline ${ }^{10}$ and is an independent risk factor for dementia. ${ }^{11}$ As such, depression and dementia appear to be associated, but the relationship between the two conditions is complex and hard to determine.

A previous study reported depression to be a risk factor for dementia, and found that eliminating depression is likely to have the biggest impact on reducing the incidence of dementia. ${ }^{12}$ Late-life depression is consistently associated with two-fold increased risk of dementia ${ }^{13}$ and clinically, it has been associated with an increased risk for dementia and Alzheimer's disease. ${ }^{14}$ The onset of depression before the age of 65 years may be a long-term risk factor for the development of dementia. ${ }^{15}$ Furthermore, considering the high prevalence of depression in young and middle-aged adults, and the long preclinical period of dementia, studies focusing on earlier-life depression may provide an opportunity to determine whether depression is a risk factor for dementia. Therefore, it is important to look at depression and dementia studies from a lifecourse approach. ${ }^{16}$

It is important to note that depression is a preventable and treatable medical condition, thereby making it a potentially modifiable factor that can prevent or delay dementia. ${ }^{17}$ In previous studies, treatment of depression in elderly depressed patients, using pharmacology, cognitive behavioural therapy and other modalities, improved cognitive function and led to improvement in memory, other aspects of cognitive performance, ${ }^{18-20}$ and pathophysiology underlying dementia. ${ }^{21} 22$ Understanding the relationship between depression and dementia can inform long-term predictive models and more rational prophylactic interventions. ${ }^{11}$ The purpose of this study was to analyse the association between dementia and depression from a life-course approach, using nationally representative data from Korea.

\section{METHODS}

\section{Data source}

The present study used data from National Health Insurance Service-National Sample Cohort (NHIS-NSC) database (DB) of the NHIS. The NHIS-NSC DB contains data for 1025340 health insurance beneficiaries and medical benefit entitlement holders (excluding foreigners) for a period of 12 years, from 2002 to 2013. The DB is a nationwide, stratified random sample of the Korean population, with 1025340 individuals in 2002 and 1014730 in 2013 , comprising approximately $2.2 \%$ of the total Korean population. The data include socio-demographic characteristics, such as disability and death, along with sex, age, region, subscriber division, income, usage of medical services (medical care and health check-up) and status of medical institutions (region, size, number of doctors, etc). The NHIS-NSC DB is known to adequately represent populations in terms of regions, insurance claims and the prevalence of major diseases. ${ }^{23}$

\section{Patient and public involvement}

There was no direct patient or public involvement in this study.

\section{Study design and population}

The present study is a nationwide retrospective propensity score matched (PSM) cohort study, aiming to determine the presence of dementia in patients with and without depression using the NHIS-NSC DB. The selection process of the case and control groups in this study is shown in figure 1.

Patients with missing sociodemographic and medical data for 11 years (2003-2013) were excluded. The case group (patients with depression) included patients newly diagnosed with depression in 2003. If depression had been diagnosed between the ages of 45 and 64 years, it was classified as 'mid-life' depression; if it was diagnosed at 65 years or above, it was classified as 'late-life' depression. Using the International Statistical Classification of Diseases and Related Health Problems, 10th revision (ICD-10), patients were included in the case group if they received a primary or secondary diagnosis of depression more than once. In this study, data from the year 2002 was not included, in order to exclude patients with preexisting depression and/or dementia. The final number of patients in the case group was 1824. The control group consisted of patients with no diagnosis of depression in 2002 and 2003, and no diagnosis of dementia in 2002. The initial number of control patients was 374852 . For each patient in the case group, age, sex, income, Charlson Comorbidity Index (CCI) score, presence of disability and area of residence were matched to randomly select the control patients, using the PSM method to balance the confounders and reduce the selection bias, ${ }^{24}$ as described in detail below. The study population is shown in figure 1 .

\section{Outcomes and other variables}

Measurement of dementia

Patients in the case and control groups were observed for newly diagnosed dementia until the end of 2013. 


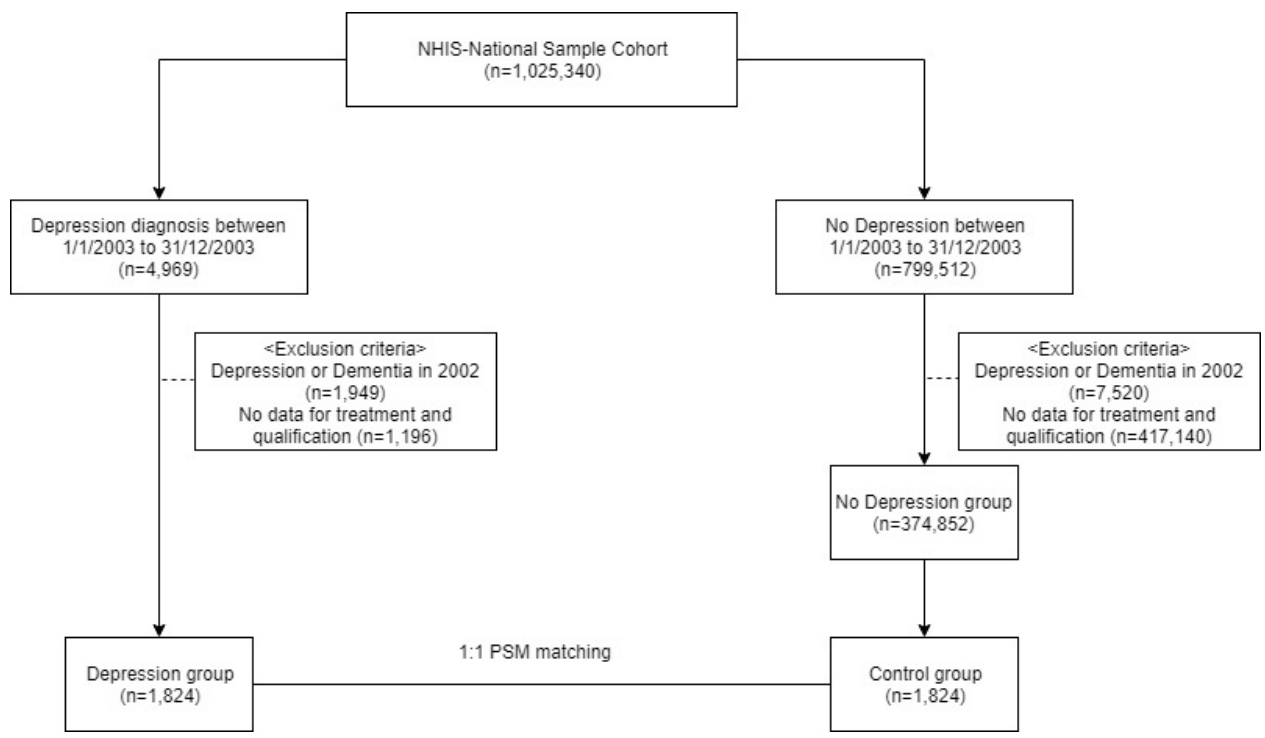

Figure 1 Flowchart of the study design. NHIS, National Health Insurance Service.

Specifically, patients were defined as having dementia when one or more ICD-10 codes for dementia were recorded as the primary or secondary diagnosis: $\mathrm{F}_{00}$ (dementia in Alzheimer's disease), $\mathrm{F}_{01}$ (vascular dementia), $\mathrm{F}_{02}$ (dementia in other diseases classified elsewhere), $\mathrm{F}_{03}$ (unspecified dementia), $\mathrm{F}_{051}$ (delirium superimposed on dementia), $G_{30}$ (Alzheimer's disease) and $\mathrm{G}_{311}$ (senile degeneration of the brain, not elsewhere classified). The primary outcome was the presence of dementia in individuals with or without depression.

\section{Measurement of depression}

Patients were defined as having depression when one or more ICD-10 codes for depression were recorded as the primary or secondary diagnosis: $\mathrm{F}_{32.0}$ (mild depressive episode), $\mathrm{F}_{32.1}$ (moderate depressive episode), $\mathrm{F}_{32.2}$ (severe depressive episode without psychotic symptoms), $\mathrm{F}_{32.3}$ (severe depressive episode with psychotic symptoms), $\mathrm{F}_{33.0}$ (recurrent depressive disorder, current episode mild), $\mathrm{F}_{33.1}$ (recurrent depressive disorder, current episode moderate), $\mathrm{F}_{33.2}$ (recurrent depressive disorder, current episode severe without psychotic symptoms) and $\mathrm{F}_{33.3}$ (recurrent depressive disorder, current episode severe with psychotic symptoms).

\section{Other variables}

Based on previous studies, we selected age, ${ }^{25-29}$ sex, ${ }^{30}$ income level, ${ }^{31}$ comorbidity, ${ }^{32}$ presence of disability ${ }^{33}$ and region $^{31}$ as covariates affecting the incidence of dementia. The specific definitions of the variables were determined as follows: through a review of previous studies, ${ }^{25-29}$ the association between depression and dementia appeared clinically in three age groups, and age was therefore categorised into three groups ( $\leq 44$ years, $45-64$ years and $\geq 65$ years). Income levels, available as deciles in the NHIS-NSC DB, were divided into three categories: low (0-3), middle (4-7) and high (8-10). ${ }^{31}$ Regions were categorised into three groups: Seoul, metropolitan cities and non-metropolitan cities. ${ }^{31}$ The CCI is an indicator of the effect a patient's illness has on mortality, and was categorised into four groups (0, 1, 2 and $\geq 3)$, using Quan's ICD-10 CCI instrument. ${ }^{34}$ The presence of disability was dichotomised as 'non-disabled' and 'disabled'.

\section{Statistical analyses}

Sociodemographic characteristics of the case and control groups were compared using the $\chi^{2}$ test before PSM. To remove selection bias from covariates in the observational data, the PSM method was used without callipers with a 1:1 nearest neighbour matching algorithm. We also used a method to exclude individuals outside of the areas where both groups were commonly observed to ensure a good balance. The covariates were age, sex, income, CCI score, presence of disability and area of residence.

After PSM, we performed a logistic regression analysis to determine the OR and $95 \%$ CI. The equations used in the logistic regressions are as follows:

$$
\begin{aligned}
& F_{0 i}=\log \frac{p_{i}}{1-p_{i}}=\beta_{0 i}+\beta_{1 i} \text { Depression }_{i} \quad \ldots \quad \text { (crude) } \\
& F_{1 i}=F_{0 i}+\beta_{2 i} \text { Gender }_{i}+\beta_{3 i} \text { Age }_{i} \quad \ldots \quad(\text { model } 1) \\
& F_{2 i}=F_{1 i}+\beta_{4 i} \text { Region }_{i}+\beta_{5 i} \text { Income }_{i} \quad \ldots \quad(\text { model } 2) \\
& F_{3 i}=F_{2 i}+\beta_{6 i} C C I_{i}+\beta_{7 i} \text { Disability }_{i} \quad \ldots \quad(\text { model 3) }
\end{aligned}
$$

where $p i$ is the probability of developing dementia for each individual $(i)$. Model 1 is adjusted for age and sex. Model 2 is obtained by additionally adjusting for income tertiles and area of residence. Finally, model 3 is obtained by modifying model 2 to include CCI score and disability type. The discriminatory power of the models was analysed using the receiver operating characteristic curve; the area under the curve (AUC) was used to determine the model fit (the closer this value is to 1 , the better is the model fit). ${ }^{35}$ All statistical analyses were performed using IBM SPSS Statistics V.25.0 (Windows; IBM) and SAS 
Table 1 Sociodemographic characteristics of the study population before propensity score matching

\begin{tabular}{|c|c|c|c|c|c|}
\hline \multirow[b]{3}{*}{ Category } & \multicolumn{2}{|c|}{ Depression (1824) } & \multicolumn{2}{|c|}{ Non-depression (374 852) } & \multirow[b]{3}{*}{$P$ value } \\
\hline & \multicolumn{2}{|c|}{ Before matching } & \multicolumn{2}{|c|}{ Before matching } & \\
\hline & $\mathrm{n}^{*}$ & $\%$ & $\mathrm{n}^{*}$ & $\%$ & \\
\hline \multicolumn{6}{|l|}{ Sex } \\
\hline Men & 501 & 27.5 & 153521 & 41 & $<0.001^{\star *}$ \\
\hline Women & 1323 & 72.5 & 221331 & 59 & \\
\hline \multicolumn{6}{|l|}{ Age (years) } \\
\hline$\leq 44$ & 741 & 40.6 & 240225 & 64.1 & \\
\hline $45-64$ & 801 & 43.9 & 102545 & 27.4 & $<0.001^{\star *}$ \\
\hline$\geq 65$ & 282 & 15.5 & 32082 & 8.6 & \\
\hline \multicolumn{6}{|l|}{ Income } \\
\hline Low (0-3) & 307 & 16.8 & 67379 & 18 & $<0.001^{* *}$ \\
\hline Middle (4-7) & 643 & 35.3 & 144560 & 38.5 & \\
\hline High (8-10) & 874 & 47.9 & 162913 & 43.5 & \\
\hline \multicolumn{6}{|l|}{ CCl score } \\
\hline 0 & 742 & 40.7 & 229980 & 61.4 & $<0.001^{* *}$ \\
\hline 1 & 766 & 42 & 116136 & 31 & \\
\hline 2 & 228 & 12.5 & 21722 & 5.8 & \\
\hline$\geq 3$ & 88 & 4.8 & 7014 & 1.9 & \\
\hline \multicolumn{6}{|l|}{ Disability type } \\
\hline Non-disabled (0) & 1757 & 96.3 & 365088 & 97.4 & 0.016 \\
\hline Disabled (1) & 67 & 3.7 & 9764 & 2.6 & \\
\hline \multicolumn{6}{|l|}{ Region } \\
\hline Seoul (0) & 389 & 21.3 & 64661 & 17.3 & $<0.001^{\star *}$ \\
\hline Metropolitan cities (1) & 424 & 23.3 & 98986 & 26.4 & \\
\hline Non-metropolitan cities (2) & 1011 & 55.4 & 211205 & 56.3 & \\
\hline
\end{tabular}

${ }^{*} \mathrm{P}<0.05 ;{ }^{* *} \mathrm{P}<0.01$

†P for trend: $\chi^{2}$ and analysis of variance.

$\mathrm{CCl}$, Charlson Comorbidity Index.

V.9.4 (SAS Institute). The level of significance was set at a two-sided $p$ value $<0.05$.

\section{RESULTS}

\section{Demographic characteristics before and after propensity} score matching

Table 1 shows the sociodemographic characteristics of patients before PSM matching. Before PSM, 72.5\% of the total number of depressed patients were women and $84.5 \%$ were younger than 65 years, indicating that depression was more common in women than men and more prevalent in younger individuals than those $\geq 65$ years of age. The percentage of patients with depression increased as the income tertile increased, reaching $47.9 \%$ in the high-income tertile (8-10).

The proportion of depressed patients with a CCI score $\geq 3$ was $4.8 \%$, whereas $40.7 \%$ had a CCI score of 0 . Furthermore, $3.7 \%$ of the depressed patients were disabled. In terms of area of residence, $21.3 \%, 23.3 \%$ and $55.4 \%$ of patients with depression resided in Seoul, metropolitan cities and non-metropolitan cities, respectively. The presence of dementia was $6.1 \%$ in the depression group. There were no significant differences in sociodemographic characteristics between the depression and non-depression group after PSM.

\section{Demographic characteristics of the study population stratified} by dementia status

Table 2 shows the socio-demographic characteristics of patients with dementia after PSM. After PSM, $83.5 \%$ of the patients with dementia were women, significantly higher than the proportion of men with dementia $(p<0.01)$. The proportion of patients $\geq 65$ years old with dementia was $65.9 \%$, significantly higher than the proportion of patients younger than 65 years with dementia $(p<0.01)$. The majority $(57.3 \%)$ of patients with dementia were in the high-income (8-10) group; the higher the income tertile, the higher the number of patients with dementia $(\mathrm{p}<0.05)$. The proportion of patients diagnosed with 
Table 2 Patient characteristics by dementia status

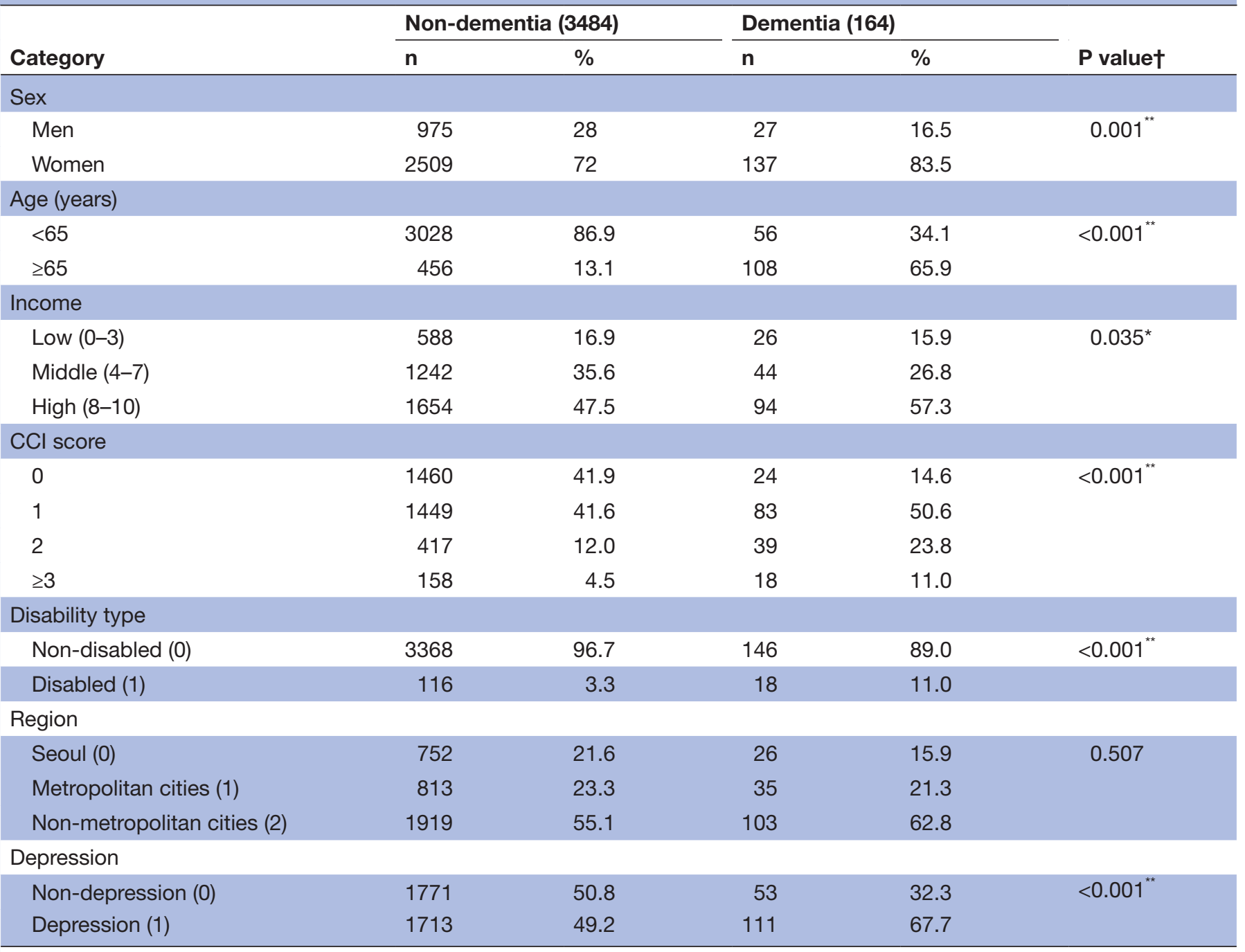

${ }^{*} \mathrm{P}<0.05 ;{ }^{* \star} \mathrm{P}<0.01$

$+\chi^{2}$ and analysis of varaince tests were performed to determine differences between groups with/without dementia.

$\mathrm{CCl}$, Charlson Comorbidity Index.

dementia with a CCI score $\geq 3$ and 0 was $11.0 \%$ and $14.6 \%$, respectively $(\mathrm{p}<0.01)$. The proportion of nondisabled patients with dementia $(89.0 \%)$ was significantly higher than that of disabled patients with dementia $(11.0 \%)(p<0.01)$. The presence of dementia was $67.7 \%$ in the depression group, indicating that dementia was significantly more prevalent in patients with depression $(p<0.01)$. There was no difference in terms of area of residence between dementia and non-dementia groups $(\mathrm{p}=0.507)$.

\section{Logistic regression analyses of factors correlated with dementia}

Table 3 shows the ORs for dementia according to depression status and covariate correction. The ORs and 95\% CI were calculated with the corresponding non-depression group as the reference. Before adjusting for all variables, the OR of developing dementia in patients with depression was $2.17(95 \% \mathrm{CI}=1.55-3.02)$ and the AUC was 0.593 . In model 1 , the OR of developing dementia was $2.09(95 \% \mathrm{CI}=1.47-2.98)$ and the AUC was 0.857 . In model 2, the OR of developing dementia was $2.11(95 \%$ $\mathrm{CI}=1.48-3.00$ ), and the AUC was 0.861. In model 3, the OR of developing dementia was 2.20 (95\% CI=1.53-3.14) and the AUC was 0.883 (highest of all the tested models).

Table 4 shows the ORs for dementia in patients with depression by sex and age. The ORs and $95 \%$ CIs were calculated using the non-depression group as reference. In model 1 , the OR of developing dementia was 2.56 (95\% CI $=1.74-3.79)$ in female patients with depression; the ORs of developing dementia in 45-64years old and $\geq 65$ years old patients with depression were 2.19 and 2.02 $(95 \% \mathrm{CI}=1.16-4.14 \%$ and $95 \% \mathrm{CI}=1.31-3.12)$, respectively. In model 2 , the OR of developing dementia in female patients was $2.58(95 \% \mathrm{CI}=1.74-3.81)$; the ORs of developing dementia in 45-64 years old and $\geq 65$ years old patients with depression were 2.25 and $2.05(95 \%$ 


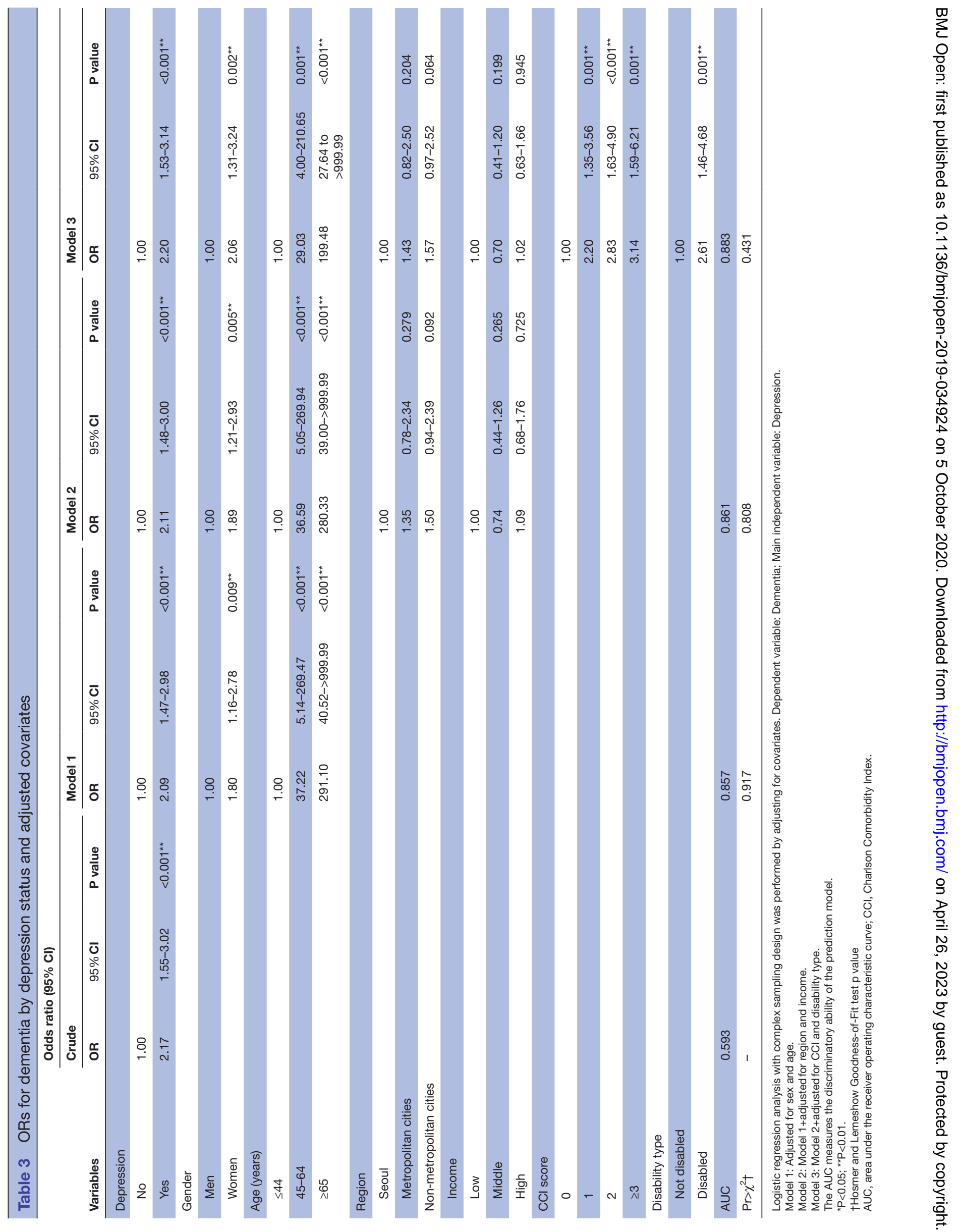


Table 4 ORs for developing dementia in patients with depression by sex and age

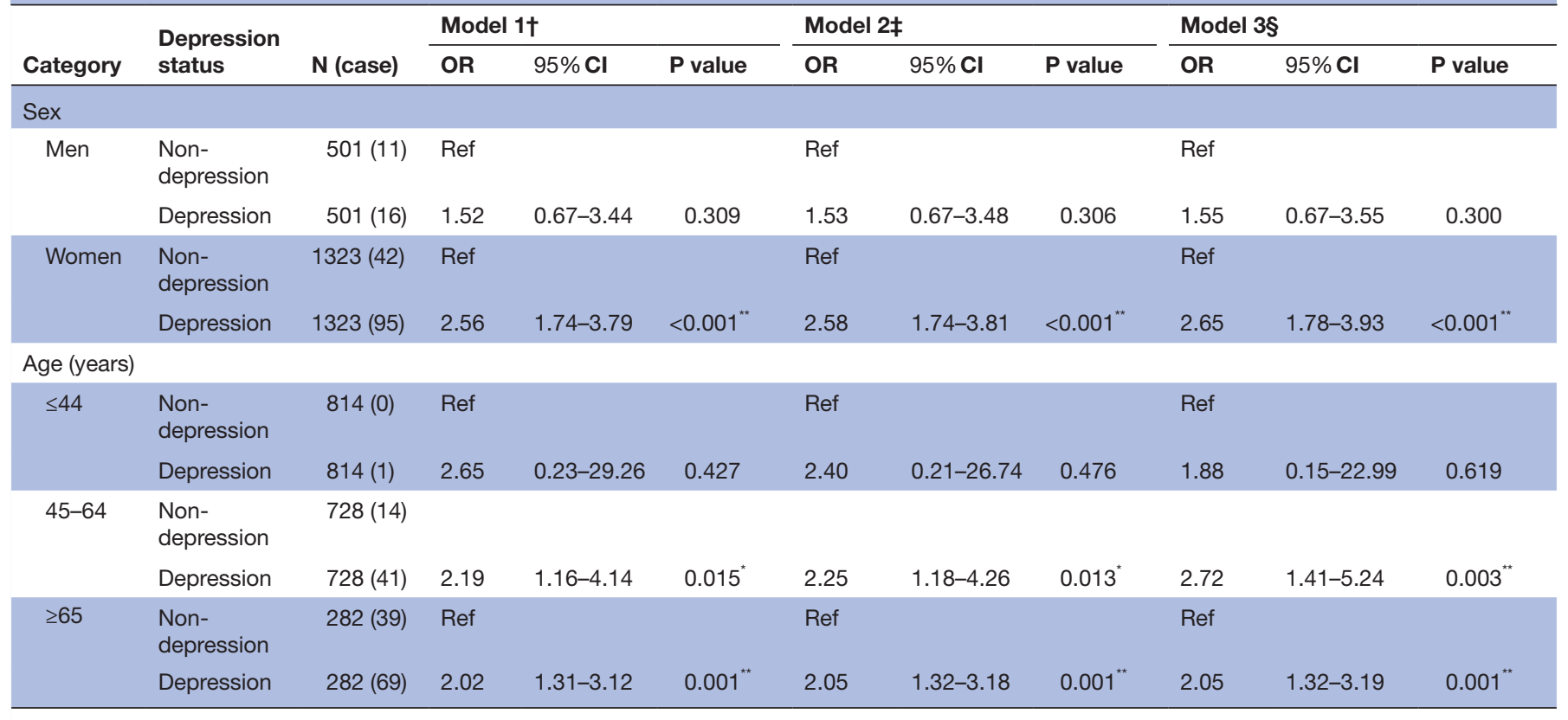

${ }^{*} \mathrm{P}<0.05 ;{ }^{* \star} \mathrm{P}<0.01$

†Model 1: Adjusted for sex and age.

¥Model 2: Model $1+$ adjusted for region and income.

§Model 3: Model 2 + adjusted for $\mathrm{CCl}$ and disability type.

$\mathrm{CI}=1.18-4.26 \%$ and $95 \% \mathrm{CI}=1.32-3.18)$, respectively. Model 3 predicted the OR of developing dementia in female patients without depression to be $2.65 \quad(95 \%$ CI=1.78-3.93); the ORs for developing dementia were 2.72 and 2.05 in patients with depression aged 45-64years and $\geq 65$ years $(95 \% \mathrm{CI}=1.41-5.24 \%$ and $95 \% \mathrm{CI}=1.32-$ 3.19 ), respectively, using age-matched patients without depression as a reference.

\section{DISCUSSION}

In this study, we have examined the ORs for developing dementia in patients with and without depression, and found that the presence of dementia was higher in patients with depression. In a subgroup analysis, depression was identified as an associated factor for dementia in women and mid-life patients. Previous studies have reported late-life depression to be closely associated with the risk of dementia. ${ }^{36-39}$ Similarly, another study found a strong association between the number of depression episodes accumulated during a follow-up period of 24 years, and the risk of dementia. ${ }^{40}$ The HR for dementia was 1.87 (95\% CI=1.21-2.88) times higher in people who experienced one episode of depression, compared with those who never experienced an episode of depression, while those who experienced episodes of depression more than twice had a HR of 2.08 (95\% CI=1.23-3.52). Interestingly, the occurrence of depressive symptoms in mid-life (40-50years) were associated with risk of Alzheimer's disease and vascular dementia. ${ }^{10}$ Moreover, previous studies have shown that depression is a risk factor for dementia and that dementia is over three times more likely to occur in women with depressive symptoms than in those without depressive symptoms. ${ }^{41}$

Other factors, such as having a low income and residing in the countryside, are also risk factors for dementia, ${ }^{42} 43$ and an impairment in physical fitness increases the chance of developing dementia. ${ }^{44}$ In this regard, the CCI score is also associated with comorbidities that act as risk factors for dementia, such as myocardial infarction, congestive heart failure, peripheral vascular disease, cerebrovascular disease and diabetes mellitus ${ }^{32}$; therefore, a high CCI score should be equally correlated with the presence of dementia. Likewise, people with intellectual disabilities and reduced cognitive function tend to develop dementia at a young age. ${ }^{45}$ In our study, the discriminatory ability of the prediction model increased after adjusting for covariates, such as gender, age, income level and CCI, which are known to be the risk factors for dementia. This was evidenced by model 3 , having the highest AUC of all the tested models $(0.883)$.

The strongest factors linking depression to dementia are vascular disease, stress-induced hippocampal atrophy, accumulation of $\beta$-amyloid plaques, inflammation and deficiency of neurotrophic factors (such as brain-derived neurotrophic factor), as reviewed elsewhere. ${ }^{15}$ Even though previous studies have reported that vascular disease can contribute to late-life depression, ${ }^{46-48}$ vascular disease has also been attributed as an effect of depression; therefore, the direction of the causality remains controversial. $^{49}{ }^{50}$ Ischaemic injury to the frontal lobe due to vascular disease has been proposed to lead to cognitive deficits, ${ }^{51}$ but studies exploring the association between 
stress hormones and hippocampal atrophy have been limited to animal studies, focusing essentially on stress responses. Nonetheless, high-stress conditions or exogenous glucocorticoids can promote nerve damage in the hippocampus, leading to memory impairment. ${ }^{52} 53$ In another study, an increase in the duration of depression was associated with a decrease in hippocampal volume. ${ }^{54}$ In contrast, a different study showed that a history of depression increases the risk of Alzheimer's disease, but not the hippocampal or amygdala volumes. ${ }^{55}$ The accumulation of hippocampal plaques and cognitive decline are more pronounced in dementia patients with a history of depression than in non-depressed patients. ${ }^{56}$ It is unclear whether depression-associated organismal changes are mechanistically linked to dementia. Possibly, cytokines, which are more abundant in depressed patients (such as interleukin-6 and tumour necrosis factor), interfere with 5-hydroxytryptamine metabolism and reduce synaptic plasticity and hippocampal neurogenesis. ${ }^{57} 58$ Another putative link between depression and dementia is a reduced activity of neurotrophic factors, such as brain-derived neurotrophic factor. ${ }^{58}$ Previous studies have shown that antidepressants such as amitriptyline, dosulepin and paroxetine are also correlated with the development of dementia. In particular, the OR was high when the dose was administered between 15 and 20 years. ${ }^{59}$ The authors reported a strong association between certain classes of anticholinergic drugs and the future incidence of dementia. This could be caused by a class-specific effect, or by drugs being used for very early symptoms of dementia.

Dementia is now a priority in many countries, for both health and social reasons. The US, Britain, France, Norway and South Korea have been developing and establishing plans and strategies for preventing dementia. ${ }^{60}$ In Korea, the first Korean National Dementia Plan was established in 2008, followed by the second in 2012, and the third in 2014; the country continues to monitor dementia at a national level. ${ }^{61}$ Even though dementia is not curable, many of its symptoms are now manageable; successful treatment can improve not only the patient's prognosis, but also help the patient's family cope with the disease. Nevertheless, prevention of dementia remains a public health priority and there is a growing interest in modifiable risk factors. An effective health policy is necessary for the prevention of dementia. ${ }^{20}$ In spite of the lack of effective treatments for dementia, ${ }^{6}$ a preventive approach may be possible by identifying high-risk individuals and addressing potentially modifiable risk factors. ${ }^{62-64}$ In particular, depression is a modifiable risk factor for dementia, ${ }^{62}$ and effective interventions for modifiable risk factors such as depression may reduce the risk of dementia. ${ }^{15}$ Some studies have shown that antidepressant drugs lead to memory enhancement and improved cognitive function. ${ }^{65}$ However, other studies have demonstrated that cognitive decline is still present after the successful treatment of depression. ${ }^{6768}$ Further clinical research is needed to determine if the risk of developing dementia is affected by treating and/ or preventing depression.

\section{Limitations}

There are several limitations of the present study that warrant discussion. First, the NHIS-NSC DB is a comprehensive $\mathrm{db}$ of diseases covered by the NHIS that reflects the entire population of Korea. ${ }^{69}$ However, due to the limitations associated with medical institutions' claims to the NHIS, it was not possible to identify the root cause of diseases, including health characteristics and nutritional intake of individuals. Early-life depression was also found to be a risk factor for dementia, but we could not determine its association with dementia because of a lack of information about the severity of depression, personal lifestyle, family history and other factors in the NHIS-NSC DB. Therefore, to better understand the mechanisms linking early-life depression to dementia, large-scale population-based prospective studies with longer follow-up periods are needed to analyse patients' individual characteristics. Additionally, it was not possible to include the income variable as an ordinal number in the model. Since income is available as deciles in the NHIS-NSC DB, income levels were divided into three categories: low (0-3), middle (4-7) and high (8-10). It should be noted that, if the income variable is analysed as a continuous variable, the results might be different.

Second, diagnostic accuracy may be limited as the data were extracted according to patients' primary diagnosis in the claims data. ${ }^{70}$ Since the diagnostic accuracy of health claims data is reported to be about $80 \%,{ }^{71}$ it is possible that some of the diagnostic codes in the data were not fully accurate. To minimise this effect and improve the accuracy of the diagnosis, this study reviewed not only the primary, but also the secondary diagnosis codes.

Third, it was not possible to confirm whether clinical interventions for depression was effective in preventing dementia. Therefore, it is necessary to understand if modifiable risk factors such as clinical depression can be targeted to prevent dementia and improve cognition. In particular, our cohort consisted of patients with a diagnosis of depression in 2003, and later diagnoses of depression were not considered in this study. Further research with a different study design will be necessary to overcome this limitation.

\section{Strengths}

This study has a number of strengths. First, we analysed data from the NHIS-NSC DB, which contains a representative sample of individuals with dementia among the Korean population. The data pertains to one million people, and were collected by medical institutions over several years before being included in the DB. This implies that the findings of this study are representative of the status of dementia and depression in Korea.

Second, previous studies assessed depressive symptoms through self-surveys, ${ }^{3637}$ interviews ${ }^{38}$ or self-tests. ${ }^{39}$ Therefore, the accuracy of the results can vary due to recall bias 
and/or a high false-positive rate of self-screening tests. ${ }^{72}$ Because the present study used ICD-10 diagnostic codes, we were able to obtain less biased results.

Third, this study used cohort data to determine the association between depression and dementia over a period of 12 years. Since most previous studies had shortterm follow-up periods, ${ }^{28-30}$ long-term effects could not be examined. In contrast, the present study confirmed the causal relationship between depression and dementia by maintaining newly diagnosed depressive patients at a ratio of 1:1 in the PSM control group in 2003, without dropout during the 10-year follow-up period. Therefore, our findings not only had adequate statistical power but also were sufficiently robust.

\section{CONCLUSIONS}

Depression is an associated factor for dementia, especially among people who are 45-64years old. Reasonable prevention and delay of dementia can be expected through an active intervention for mid-life depression.

\section{Author affiliations}

${ }^{1}$ Department of Korean rehabilitation medicine, Janseng Hospital of Korean Medicine, Seoul, Republic of Korea

${ }^{2}$ Department of Health Administration, Hanyang Women's University, Seoul, Republic of Korea

${ }^{3}$ Korean Internal Medicine, Semyung University, Korea, Chungju, Republic of Korea ${ }^{4} \mathrm{Herbal}$ medicine policy division, Ministry of Food and Drug safety, Sejong-si, Republic of Korea

${ }^{5}$ National Agency for Development of Innovative Technologies in Korean Medicine, National Institute of Korean Medicine Development, Seoul, Republic of Korea

${ }^{6}$ Department of clinical research, Jaseng Spine and Joint Research Institute, Jaseng Medical Foundation, Seoul, Republic of Korea

Contributors $\mathrm{I}-\mathrm{HH}$ and $\mathrm{BJ}$ contributed to the overall conception and design of the study protocol. 0-CY and BJ contributed to the specific study design and data analysis. 0-CY and BJ wrote the first draft of the manuscript. $\mathrm{HG}$ and MP contributed to interpretation of the analyses and revisions of the final manuscript. All authors gave final approval of the version to be submitted.

Funding The authors have not declared a specific grant for this research from any funding agency in the public, commercial or not-for-profit sectors.

Competing interests None declared.

Patient consent for publication Not required.

Ethics approval This study was approved by the Institutional Review Board of Jaseng Hospital of Korean Medicine in Seoul, Korea (JASENG 2018-12-005), with a waiver for informed consent because the data were obtained from a public database (https://www.khp.re.kr:444/eng/data/data.do); all personal information was de-identified by the NHIS prior to public release. The principles expressed in the Declaration of Helsinki have been adhered to in this study.

Provenance and peer review Not commissioned; externally peer reviewed.

Data availability statement Data are available in a public, open access repository. The datasets generated and analysed during the current study are available on the National Health Insurance Sharing Service. NHIS provides support to research activities in various sectors of society, including the economy, environment and industry, as well as policy and academic research in the health sector, by providing sample cohort databases. The research database consists of five types of databases: sample cohort, medical check-up cohort, elderly cohort, working women cohort and infant medical check-up cohort. Each cohort database consists of the following four detailed data sets: qualification, treatment, medical check-up and clinic.The present study utilised the sample cohort database, which is third-party data, not owned by the authors. The sample cohort database is available upon approval for data sharing from the health insurance corporation. For the purposes of policy and academic research, a fee is paid to obtain the data from the NHIS website (https://nhiss.nhis.or.kr/bd/ab/bdaba022eng.do).

Open access This is an open access article distributed in accordance with the Creative Commons Attribution Non Commercial (CC BY-NC 4.0) license, which permits others to distribute, remix, adapt, build upon this work non-commercially, and license their derivative works on different terms, provided the original work is properly cited, appropriate credit is given, any changes made indicated, and the use is non-commercial. See: http://creativecommons.org/licenses/by-nc/4.0/.

\section{ORCID iDs}

Boyoung Jung http://orcid.org/0000-0001-9812-0745

In-Hyuk Ha http://orcid.org/0000-0002-5020-6723

\section{REFERENCES}

1 Carone M, Asgharian M, Jewell NP. Estimating the lifetime risk of dementia in the Canadian elderly population using cross-sectional cohort survival data. J Am Stat Assoc 2014;109:24-35.

2 Wimo A, Guerchet M, Ali G-C, et al. The worldwide costs of dementia 2015 and comparisons with 2010. Alzheimers Dement 2017;13:1-7.

3 Alzheimer's Association. 2018 Alzheimer's disease facts and figures. Alzheimer's \& Dementia 2018;14:367-429.

$4 \mathrm{Kim} \mathrm{S}$, Lee C. Status and improvement tasks of dementia management plan. Seoul: National Assembly Budget Office, 2014.

5 Kawas $\mathrm{CH}$, Brookmeyer R. Aging and the public health effects of dementia. N Engl J Med 2001;344:1160-1.

6 Alzheimer's Disease International. World Alzheimer Report 2019 Attitudes to dementia. London Alzheimer's Disease International (ADI); 2019

7 Korea Ministry of Health and Welfare. Nationwide survey on the dementia epidemiology of Korea 2016 National Institute of Dementia; 2018: 3-4.

8 Zubenko GS, Zubenko WN, McPherson S, et al. A collaborative study of the emergence and clinical features of the major depressive syndrome of Alzheimer's disease. Am J Psychiatry 2003;160:857-66.

9 Steffens DC, Potter GG. Geriatric depression and cognitive impairment. Psychol Med 2008;38:163-75.

10 Rapp MA, Schnaider-Beeri M, Wysocki M, et al. Cognitive decline in patients with dementia as a function of depression. Am J Geriatr Psychiatry 2011;19:357-63.

11 Diniz BS, Butters MA, Albert SM, et al. Late-Life depression and risk of vascular dementia and Alzheimer's disease: systematic review and meta-analysis of community-based cohort studies. Br J Psychiatry 2013;202:329-35.

12 Ritchie K, Carrière I, Ritchie CW, et al. Designing prevention programmes to reduce incidence of dementia: prospective cohort study of modifiable risk factors. BMJ 2010;341:c3885.

13 Cherbuin N, Kim S, Anstey KJ. Dementia risk estimates associated with measures of depression: a systematic review and meta-analysis. BMJ Open 2015;5:e008853.

14 Santabarbara J, Sevil-Perez A, Olaya B, et al. [Clinically relevant late-life depression as risk factor of dementia: a systematic review and meta-analysis of prospective cohort studies]. Rev Neurol 2019;68:493-502.

15 Kessing LV. Depression and the risk for dementia. Curr Opin Psychiatry 2012;25:457-61.

16 Byers AL, Yaffe K. Depression and risk of developing dementia. Nat Rev Neurol 2011;7:323-31.

17 Reynolds CF, Cuijpers P, Patel V, et al. Early intervention to reduce the global health and economic burden of major depression in older adults. Annu Rev Public Health 2012;33:123-35.

18 Wuthrich VM, Rapee RM, Draper B, et al. Reducing risk factors for cognitive decline through psychological interventions: a pilot randomized controlled trial. Int Psychogeriatr 2018;31:1015-25.

19 Doraiswamy PM, Krishnan KRR, Oxman T, et al. Does antidepressant therapy improve cognition in elderly depressed patients? J Gerontol A Biol Sci Med Sci 2003;58:M1137-44.

20 Areán PA, Raue P, Mackin RS, et al. Problem-Solving therapy and supportive therapy in older adults with major depression and executive dysfunction. Am J Psychiatry 2010;167:1391-8.

21 Hashioka S, McGeer PL, Monji A, et al. Anti-Inflammatory effects of antidepressants: possibilities for preventives against Alzheimer's disease. Cent Nerv Syst Agents Med Chem 2009;9:12-19.

22 Groves JO. Is it time to reassess the BDNF hypothesis of depression? Mol Psychiatry 2007;12:1079-88.

23 Lee J, Lee JS, Park S-H, et al. Cohort profile: the National health insurance Service-National sample cohort (NHIS-NSC), South Korea. Int J Epidemiol 2017;46:e15. 
24 D'Agostino RB. Propensity score methods for bias reduction in the comparison of a treatment to a non-randomized control group. Stat Med 1998;17:2265-81.

25 Livingston G, Sommerlad A, Orgeta V, et al. Dementia prevention, intervention, and care. Lancet 2017;390:2673-734.

26 Mukadam N, Sommerlad A, Huntley J, et al. Population attributable fractions for risk factors for dementia in low-income and middleincome countries: an analysis using cross-sectional survey data. Lancet Glob Health 2019;7:e596-603.

27 Orgeta V, Mukadam N, Sommerlad A, et al. The Lancet Commission on dementia prevention, intervention, and care: a call for action. Ir J Psychol Med 2019;36:85-8.

28 Knopman DS, Gottesman RF, Sharrett AR, et al. Midlife vascular risk factors and midlife cognitive status in relation to prevalence of mild cognitive impairment and dementia in later life: the Atherosclerosis risk in Communities study. Alzheimers Dement 2018;14:1406-15.

29 Smith JS, Kiloh LG. The investigation of dementia: results in 200 consecutive admissions. Lancet 1981:1:824-7.

30 Fuhrer R, Antonucci TC, Gagnon M, et al. Depressive symptomatology and cognitive functioning: an epidemiological survey in an elderly community sample in France. Psychol Med 1992;22:159-72.

$31 \mathrm{Kim} \mathrm{J}-\mathrm{H}$, Lee $\mathrm{Y}$. Dementia and death after stroke in older adults during a 10-year follow-up: results from a competing risk model. $J$ Nutr Health Aging 2018;22:297-301.

32 Lin W-C, Hu L-Y, Tsai S-J, et al. Depression and the risk of vascular dementia: a population-based retrospective cohort study. Int $J$ Geriatr Psychiatry 2017;32:556-63.

33 Jeong S-M, Shin DW, Lee JE, et al. Anemia is associated with incidence of dementia: a national health screening study in Korea involving 37,900 persons. Alzheimers Res Ther 2017:9:94

34 Quan H, Sundararajan V, Halfon P, et al. Coding algorithms for defining comorbidities in ICD-9-CM and ICD-10 administrative data. Med Care 2005;43:1130-9.

35 Tang Z-H, Liu J, Zeng F, et al. Comparison of prediction model for cardiovascular autonomic dysfunction using artificial neural network and logistic regression analysis. PLoS One 2013;8:e70571.

36 Lindsay J, Laurin D, Verreault R, et al. Risk factors for Alzheimer's disease: a prospective analysis from the Canadian study of health and aging. Am J Epidemiol 2002;156:445-53.

37 Hébert R, Lindsay J, Verreault R, et al. Vascular dementia : incidence and risk factors in the Canadian study of health and aging. Stroke 2000;31:1487-93.

38 Andersen K, Lolk A, Kragh-Sørensen P, et al. Depression and the risk of Alzheimer disease. Epidemiology 2005;16:233-8.

39 Gatz JL, Tyas SL, St John P, et al. Do depressive symptoms predict Alzheimer's disease and dementia? J Gerontol A Biol Sci Med Sci 2005;60:744-7.

40 Dotson VM, Beydoun MA, Zonderman AB. Recurrent depressive symptoms and the incidence of dementia and mild cognitive impairment. Neurology 2010;75:27-34.

41 Spira AP, Rebok GW, Stone KL, et al. Depressive symptoms in oldest-old women: risk of mild cognitive impairment and dementia. Am J Geriatr Psychiatry 2012;20:1006-15.

42 Anttila T, Helkala E-L, Kivipelto M, et al. Midlife income, occupation, APOE status, and dementia: a population-based study. Neurology 2002;59:887-93.

43 Jia J, Wang F, Wei C, et al. The prevalence of dementia in urban and rural areas of China. Alzheimers Dement 2014;10:1-9.

44 Song X, Mitnitski A, Rockwood K. Age-Related deficit accumulation and the risk of late-life dementia. Alzheimers Res Ther 2014:6:54.

45 Strydom A, Livingston G, King M, et al. Prevalence of dementia in intellectual disability using different diagnostic criteria. $\mathrm{Br} \mathrm{J}$ Psychiatry 2007;191:150-7.

46 Teodorczuk A, O'Brien JT, Firbank MJ, et al. White matter changes and late-life depressive symptoms: longitudinal study. $\mathrm{Br} J$ Psychiatry 2007;191:212-7.

47 Rao R. Cerebrovascular disease and late life depression: an age old association revisited. Int J Geriatr Psychiatry 2000;15:419-33.

48 Alexopoulos GS, Meyers BS, Young RC, et al. 'Vascular depression' hypothesis. Arch Gen Psychiatry 1997;54:915-22.

49 Van der Kooy K, van Hout H, Marwijk H, et al. Depression and the risk for cardiovascular diseases: systematic review and meta analysis. Int J Geriatr Psychiatry 2007;22:613-26.
50 Pan A, Sun Q, Okereke Ol, et al. Depression and risk of stroke morbidity and mortality: a meta-analysis and systematic review. JAMA 2011;306:1241-9.

51 Alexopoulos GS. The vascular depression hypothesis: 10 years later. Biol Psychiatry 2006;60:1304-5.

52 Colla M, Kronenberg G, Deuschle M, et al. Hippocampal volume reduction and HPA-system activity in major depression. J Psychiatr Res 2007;41:553-60.

53 Cereseto M, Reinés A, Ferrero A, et al. Chronic treatment with high doses of corticosterone decreases cytoskeletal proteins in the rat hippocampus. Eur J Neurosci 2006;24:3354-64.

54 Park CR, Zoladz PR, Conrad CD, et al. Acute predator stress impairs the consolidation and retrieval of hippocampus-dependent memory in male and female rats. Learn Mem 2008;15:271-80.

55 Geerlings Ml, den Heijer T, Koudstaal PJ, et al. History of depression, depressive symptoms, and medial temporal lobe atrophy and the risk of Alzheimer disease. Neurology 2008;70:1258-64.

56 Rapp MA, Schnaider-Beeri M, Grossman HT, et al. Increased hippocampal plaques and tangles in patients with Alzheimer disease with a lifetime history of major depression. Arch Gen Psychiatry 2006;63:161-7.

57 Sorrells SF, Sapolsky RM. An inflammatory review of glucocorticoid actions in the CNS. Brain Behav Immun 2007;21:259-72.

58 Caraci F, Copani A, Nicoletti F, et al. Depression and Alzheimer's disease: neurobiological links and common pharmacological targets. Eur J Pharmacol 2010;626:64-71.

59 Richardson K, Fox C, Maidment I, et al. Anticholinergic drugs and risk of dementia: case-control study. BMJ 2018;361:k1315.

60 Prince M, Bryce R, Albanese E, et al. The global prevalence of dementia: a systematic review and metaanalysis. Alzheimers Dement 2013:9:63-75.

61 Lee DW, Seong S-J. Korean national dementia plans: from 1st to 3rd. $J$ Korean Med Assoc 2018;61:298.

62 Norton S, Matthews FE, Barnes DE, et al. Potential for primary prevention of Alzheimer's disease: an analysis of population-based data. Lancet Neurol 2014;13:788-94.

63 Ngandu T, Lehtisalo J, Solomon A, et al. A 2 year multidomain intervention of diet, exercise, cognitive training, and vascular risk monitoring versus control to prevent cognitive decline in at-risk elderly people (FINGER): a randomised controlled trial. Lancet 2015;385:2255-63.

64 Moll van Charante EP, Richard E, Eurelings LS, et al. Effectiveness of a 6-year multidomain vascular care intervention to prevent dementia (preDIVA): a cluster-randomised controlled trial. Lancet 2016;388:797-805

65 Herrera-Guzmán I, Gudayol-Ferré E, Herrera-Guzmán D, et al. Effects of selective serotonin reuptake and dual serotonergic-noradrenergic reuptake treatments on memory and mental processing speed in patients with major depressive disorder. $J$ Psychiatr Res 2009:43:855-63.

66 Mowla A, Mosavinasab M, Pani A. Does fluoxetine have any effect on the cognition of patients with mild cognitive impairment? A doubleblind, placebo-controlled, clinical trial. J Clin Psychopharmacol 2007;27:67-70.

67 Devanand DP, Pelton GH, Marston K, et al. Sertraline treatment of elderly patients with depression and cognitive impairment. Int $J$ Geriatr Psychiatry 2003;18:123-30.

68 Bhalla RK, Butters MA, Mulsant BH, et al. Persistence of neuropsychologic deficits in the remitted state of late-life depression. Am J Geriatr Psychiatry 2006;14:419-27.

69 Seong SC, Kim Y-Y, Park SK, et al. Cohort profile: the National health insurance service-national health screening cohort (NHIS-HEALS) in Korea. BMJ Open 2017;7:e016640.

$70 \mathrm{Kim}$ JA, Yoon S, Kim LY, et al. Towards actualizing the value potential of Korea health insurance review and assessment (HIRA) data as a resource for health research: strengths, limitations, applications, and strategies for optimal use of HIRA data. J Korean Med Sci 2017;32:718-28.

71 Park E-C. Health insurance claim disease code and medical record consistency evaluation and improvement plan research. Available: http://www.alio.go.kr/informationResearchView.do?seq=2343982

72 Thombs BD, Coyne JC, Cuijpers P, et al. Rethinking recommendations for screening for depression in primary care. CMAJ 2012;184:413-8. 